\title{
O Lugar da Análise do Comportamento no Debate Científico Contemporâneo
}

\author{
Carolina Laurenti ${ }^{1}$ \\ Universidade Estadual de Maringá
}

\begin{abstract}
RESUMO - A ciência sofreu várias transformações ao longo da história. Assiste-se no terreno científico-filosófico contemporâneo a mais uma mudança: a crise do modelo de ciência moderno e a emergência de uma diferente proposta científica, a ciência pós-moderna. Skinner disse que a Análise do Comportamento e sua filosofia, o Behaviorismo Radical, são capazes de instruir o discurso da filosofia da ciência. Não obstante, o texto skinneriano tem uma abertura para dialogar tanto com o modelo de ciência moderno quanto pós-moderno. O objetivo deste texto é examinar alguns compromissos filosóficos (ontológicos, epistemológicos e éticos) das diferentes propostas de ciência skinneriana a fim de esclarecer possibilidades de inserção da Análise do Comportamento nesse debate.
\end{abstract}

Palavras-chave: ciências moderna e pós-moderna; ciência skinneriana; empirismo; positivismo; pragmatismo; darwinismo; ética.

\section{The Place of Behavior Analysis in the Contemporary Scientific Debate}

\begin{abstract}
Science has experienced several changes in the course of history. The contemporary scientific-philosophical field is witnessing a new change: the crisis in the modern science model and the emerging of a different scientific proposal, the post-modern science. Skinner affirmed that Behavior Analysis and its philosophy, Radical Behaviorism, are able to enlighten the discourse of philosophy of science. Nevertheless, Skinner's work permits discussing not only the modern science model but the post-modern as well. This text intends to examine some philosophical commitments (ontological, epistemological and ethical) of the diverse Skinnerian scientific proposals in order to clarify possibilities of placing Behavior Analysis in this debate.
\end{abstract}

Keywords: modern and post-modern sciences; Skinnerian science; empiricism; positivism; pragmatism; Darwinism; ethics.

Nos últimos dois séculos a ciência tem sofrido mudanças profundas em seus aspectos mais basilares, configurando um modelo diferente de ciência (Santos, 1987/2004). Esse paradigma emergente tem recebido diversas designações, dentre elas, a de ciência pós-moderna (Santos, 1989/2003). O termo pós-moderno é "controverso e ambíguo" (Kvale, 1992/1994, p. 02), tanto que há várias discussões sobre sua adequação e pertinência: há aqueles que evitam seu emprego (Giddens, 2003), outros que o abandonaram (Bauman, 2001), outros ainda que insistem em seu uso (Lyotard, 1979; Santos, 1987/2004, 1989/2003). Além disso, aqueles que empregam o termo pós-moderno, não raro, o fazem em diferentes contextos - como cultura, arte, literatura, mídia, filosofia, ciência, ética, estética - com sentidos diversos (Kvale, 1992/1994).

Mas, a despeito dessas dificuldades, a expressão "ciência pós-moderna" será adotada neste texto, pois parece ser útil para arrolar um conjunto de mudanças que tem ocorrido no âmbito científico. Nesse sentido, a proposta do sociólogo português Boaventura de Sousa Santos (1940-) será seguida aqui, para quem o termo pós-moderno tem uma acepção positiva, caracterizando um projeto cultural, do qual fazem parte mudanças científicas (Santos, 1987/2004, 2000). Em seu uso científico, pós-moderno designa, então, um modelo de ciência ainda não completamente definido, que surgiu

1 Endereço para correspondência: Universidade Estadual de Maringá, Centro de Ciências Humanas Letras e Artes, Departamento de Fundamentos da Educação. Av. Colombo, n. 5790 - Bloco I 12 - sala 10. Jardim Universitário. CEP: 87020-900 - Maringá, PR - Brasil. E-mail: laurenticarol@gmail.com como resultado da derrocada do modelo de ciência moderno (Santos, 1987/2004, 1989/2003) - um paradigma inaugurado no século XVI e vigente até o final do século XIX (Köche, 2002; Santos, 1987/2004). Com efeito, a expressão "ciência pós-moderna" qualifica uma série de transformações que sinaliza uma superação em relação aos preceitos da ciência moderna (Santos, 1987/2004, 1989/2003).

No contexto da emergência desse novo paradigma tem ocorrido um vigoroso debate acerca dos compromissos ontológicos, epistemológicos e éticos do fazer científico. Participam dessa discussão diferentes ciências como Física (Earman, 1986; Heisenberg, 1958/1999, 2000/2004), Química (Prigogine, 2003), Biologia (Lewontin, 1998/2002; Mayr, 2004/2005), Sociologia (Bourdieu, 1983; Santos, 2000), Antropologia (Geertz, 1973) ${ }^{2}$. Diante desse quadro de intenso e rico debate nas ciências, como a Análise Comportamento pode se inserir nessa discussão? Examinar essa questão é o objetivo deste texto. Para tanto, será realizada inicialmente uma descrição sucinta do modelo moderno de ciência, que servirá como pano de fundo contra o qual serão esboçadas as principais características da proposta científica pós-moderna. Por fim, a ciência skinneriana será alvo de exame mais atento, a fim de encontrar aspectos que permitam delimitar o seu lugar nesse cenário.

2 Embora muitos desses autores não se intitulem "pós-modernos", as críticas que fazem aos preceitos da ciência moderna justificam o fato de eles serem arrolados sob essa rubrica. Isso porque, como já foi mencionado, a expressão ciência pós-moderna é empregada, aqui, como um recurso heurístico útil para sistematizar, não só as críticas ao modelo moderno de ciência, mas também as propostas alternativas do fazer científico que emergem em função dessas críticas. 


\section{Ciência moderna}

O paradigma moderno de ciência define-se, em linhas gerais, pela crença em um mundo ordenado, do qual não participam relações variáveis ou incertas "... admito que o mundo seja um corpo dotado de todas as dimensões e, por isso mesmo, perfeitíssimo; e acrescento que como tal é necessariamente ordenadíssimo, ou seja, formado de partes dispostas entre si com máxima e perfeitíssima ordem" (Galilei, 1632/2004, p. 99). Trata-se, pois, de um mundo constituído por relações causais inexoráveis entre eventos (Bacon, 1620/1979; Laplace, 1814/1951; Mill, 1843/1979). Essas relações causais podem ser conhecidas, desde que a ciência se restrinja aos fatos, obtidos por meio de uma observação sistemática e purificada de valores advindos do contexto sócio-cultural e da subjetividade do próprio pesquisador (Bacon, 1620/1979, pp. 21-32). Assim, a objetividade do conhecimento científico seria garantida pela possibilidade de uma observação isenta de compromissos com os interesses de qualquer perspectiva de valor particular (neutralidade científica).

A ciência moderna subscreve, então, a dicotomia entre fatos e valores, na qual os fatos são independentes de qualquer juízo valorativo. Os fatos encerram descrições causais entre eventos observáveis, cujo caráter inexoravelmente ordenado pode fundamentar o conhecimento legítimo. Já os valores incorporam emoções e sentimentos; e por serem pessoais, relativos e irregulares não podem alicerçar o conhecimento verdadeiro. Essa desqualificação dos valores, anunciada desde Bacon, esteve presente em Copérnico e Newton, e foi atualizada pelo programa positivista lógico de ciência, que não outorgou aos valores significado cognitivo (Mariconda, 2006). Com efeito, as questões de fato (objetivas) foram reservadas à ciência; e as de valor (subjetivas) aos campos da ética, política, estética, religião e senso comum.

Além disso, na ciência moderna a obtenção de relações causais entre eventos observáveis (fatos) é promovida por um meio de acesso privilegiado ao real: o método quantitativo-experimental que, mediante a manipulação e controle rigorosos de variáveis, é capaz de descobrir relações de dependência entre tipos de eventos (Köche, 2002). Uma vez descobertas, conexões entre esses fatos são expressas na forma de leis universais, que especificam relações de necessidade e suficiência causal (Bacon, 1620/1979, pp. 9598). Essas leis devem integrar um sistema cujo critério de excelência é aferido pela simplicidade e generalidade: entre dois sistemas, aquele que lograr a explicação de uma gama de fatos com o menor número de princípios deve ser considerado verdadeiro (Bacon, 1620/1979, pp. 96-98, 124-125). Subentende-se, portanto, que a natureza é simples e simétrica, e que a teoria que conseguir reduzir a complexidade a uma linguagem igualmente simples e simétrica terá, então, condições de ler o "livro da natureza" (o universo). Esse livro, diz Galilei (1623/1987), "está escrito em língua matemática, os caracteres são triângulos, circunferências e outras figuras geométricas..." (p. 21). Tendo descrito as regularidades da natureza nesse idioma e organizado-as em um conjunto de princípios e leis simples, a ciência será, então, capaz de prever os fenômenos da natureza com certeza absoluta (Mill, 1843/1979, p. 191).
Uma vez que a ciência moderna concebe o mundo como imutável, seus problemas e desafios alocam-se no nível estritamente epistemológico: é preciso encontrar teorias, métodos e técnicas cada vez mais eficazes na tentativa de apreender essa realidade (Laplace, 1814/1951). Nesse processo de busca pela certeza, descrições da realidade em termos de probabilidade, leis estatísticas e previsões imprecisas revelam apenas nossa ignorância temporária das verdadeiras causas do fenômeno - uma limitação que supostamente será suplantada pelo avanço científico (Laplace, 1814/1951; Mill, 1843/1979). Mill esclarece:

Devemos nos lembrar de que a probabilidade de um evento não é qualidade do próprio evento, mas mero nome para uma medida de fundamento que nós ou qualquer outra pessoa tem para esperá-lo. (. . .) Todo evento é em si mesmo certo, não provável; se soubéssemos tudo, ou saberíamos positivamente que iria acontecer, ou saberíamos positivamente que não. Mas sua probabilidade significa para nós o grau de expectativa de sua ocorrência que estamos autorizados a nutrir pela nossa certeza atual. (Mill, 1843/1979, p. 249)

Resumindo: para a ciência moderna o conhecimento científico genuíno está assentado em bases sólidas, constituídas por relações certas e absolutas entre eventos (Bacon, 1620/1979; Laplace, 1814/1951). Como as ciências humanas debruçam-se sobre fenômenos que não se acomodam a esses cânones, elas são geralmente tratadas como "ciências menores", já que, no máximo, podem aduzir leis estatísticas de seus objetos de estudo. Com efeito, as relações entre os campos científicos no contexto da ciência moderna são hierárquicas e unilaterais, tal como se verifica na classificação comtiana das ciências (Comte, 1830-42/1978). Seguindo os critérios de simplicidade e generalidade de seu objeto de estudo, Comte (pp. 33-34, 38-39) distribui as ciências em ordem decrescente de importância da seguinte maneira: matemática, astronomia, física, química, filosofia e física social (sociologia). Nessa pirâmide as ciências que ocupam uma posição superior podem influenciar as de grau inferior, porém, aquelas não podem ser influenciadas por estas.

Diante desse quadro, restariam poucas alternativas às ciências humanas. De um lado, elas poderiam se inscrever no programa reducionista de ciência, no qual o estatuto científico é assegurado pela redução de teorias àquelas sobre as quais não pairam dúvidas sobre sua cientificidade. Sob essa ótica, as ciências humanas reduziriam suas leis às da física ou química, já que essas desfrutam de um status científico mais privilegiado (Santos, 1987/2004). Outra possibilidade seria tentar reivindicar um estatuto epistêmico próprio, com linguagem, objetivos, conceitos, métodos e técnicas adequados ao seu fenômeno de interesse. Trata-se, pois, de um fenômeno complexo, espontâneo, criativo e intencional, diferindo do caráter mecanicista e determinista do objeto das ciências naturais.

É importante notar que, a despeito das diferenças entre o programa reducionista e o que reivindica um estatuto científico distinto para as ciências humanas, ambos são subsidiários do modelo de racionalidade das ciências naturais (Santos, 1987/2004). Isso porque as ciências humanas reclamam um modo de explicação diferente das ciências 
naturais com base na suposição de que o homem não se identifica com a natureza. Esta é simples e mecânica, aquele é dotado de complexidade e intencionalidade. Em outras palavras, a defesa do caráter único do ser humano pelas ciências humanas se dá em contraposição à visão mecanicista e determinista de natureza - exatamente a mesma concepção defendida pelas ciências naturais. Desse modo, ao invés de suplantar, as ciências humanas endossam a visão mecânico-determinista de natureza, e acabam, no limite, acirrando a dicotomia homem-natureza, típica do pensamento moderno (Santos, pp. 39-40).

\section{Ciência pós-moderna}

Críticas ao paradigma científico moderno vêm de várias frentes na ciência e filosofia das ciências (Bourdieu, 1983; Heisenberg, 1958/1999; Kuhn, 2006; Lewontin, 1998/2002; Mayr, 2004/2005; Morin, 1999; Popper, 1956/1988; Prigogine, 2003; Santos, 1987/2004, 2000). A despeito das especificidades de cada uma dessas críticas, elas podem ser tomadas em conjunto, pois permitem, mesmo que por oposição ou contraste, esboçar a feição do paradigma emergente ou pós-moderno. Tais críticas parecem ter um alvo comum: a pretensão da ciência moderna em alcançar certezas, que se fundamenta na crença em uma realidade imutável e determinada.

Diferentemente da visão moderna de ciência, o modelo pós-moderno entende a realidade como algo inacabado e em constante transformação (Santos, 1987/2004, 1989/2003). Trata-se, pois, de um universo indeterminista - um sistema em que o presente não fixa de maneira inequívoca o futuro, sendo compatível com inúmeras possibilidades de realização (Prigogine, 2003; Popper, 1956/1988). Sob esse prisma, "o mundo não é mais uma máquina causal - pode ser visto a partir de agora como um mundo de propensões, como um processo contínuo de realização de possibilidades e do desdobramento de novas possibilidades" (Popper, conforme citado por Miller, 1995/1997, p. 174).

Embora a existência de leis probabilísticas seja um fato amplamente aceito na ciência, mesmo em sua versão moderna, sua explicação é diferente na proposta científica pós-moderna: a probabilidade não diz respeito apenas ao elevado número de variáveis que operam na realidade, mas ao fato de a realidade ser, ela mesma, probabilística (Heisenberg, 1958/1999; Popper, 1956/1988; Prigogine, 2003). Dito de outro modo, a probabilidade não é mais entendida como uma confissão da ignorância da causas, mas sim, descreve um aspecto objetivo do mundo: "[a probabilidade] introduz algo entre a ideia de evento e o evento concreto, um tipo estranho de realidade física que se encontra justamente entre a possibilidade e a realidade" (Heisenberg, 2000/2004, p. 41). Por conseguinte, quanto mais a ciência se aproxima da realidade, mais suas leis e previsões serão probabilísticas. Sobre esse último ponto, Heisenberg (2000/2004, p. 16) esclarece: "as leis da natureza formuladas em termos matemáticos não mais determinam os próprios fenômenos, mas a possibilidade de ocorrência, a probabilidade de que algo ocorrerá". Tal concepção já tinha sido sinalizada por Peirce (1892/1992) no fim do século XIX: "tente verificar qualquer lei da natureza e você descobrirá que quanto mais suas observações forem precisas, com mais certeza elas mostrarão desvios irregulares da lei" (pp. 304-305).

Nessa perspectiva, a meta da ciência não se identifica mais com a busca da certeza por meio da observação pura, e pelo emprego de um único método que permita um acesso privilegiado a essa realidade (Morin, 1999; Prigogine, 2003). Como a realidade é mutável e plural, a discussão metodológica ganha outro tom: exige criatividade do cientista para inventar e reformular métodos que possam dialogar com essa realidade mutável. Para tanto, o cientista deve transgredir seu campo e invadir fronteiras de outras áreas científicas. A epistemologia pós-moderna é, por isso, marcada pela pluralidade metodológica e pela transdisciplinaridade (Morin, 1999; Santos, 1987/2004). Não obstante, advogar a diversidade de métodos não é o mesmo que defender o uso de qualquer método. A escolha do método deve respeitar as características do fenômeno a ser investigado, cujos contornos envolvem reflexão e estudo sistemático sobre sua natureza e suas possibilidades de conhecimento.

Ademais, a pluralidade metodológica exige das ciências a capacidade de estabelecer um diálogo legítimo e virtuoso com outros campos científicos. Isso será possível mediante o abandono de duas noções caras à ciência moderna: a simplificação e a redução. Reconhecendo que a natureza não é simples, mas complexa, a ciência pós-moderna admite vários níveis de emergência da realidade. Sob esse prisma, o diálogo entre domínios científicos distintos "é a comunicação com base num pensamento complexo" (Morin, 1990/2008, p. 140). Esses diferentes níveis da realidade são identificados por distinção, divisão e separação. Não obstante, tais atividades podem operar sem redução de um nível a outro. Com efeito, a transdisciplinaridade da ciência pós-moderna é a comunicação sem redução (Morin, 1990/2008). É pautando-se em uma filosofia anti-reducionista, defensora da autonomia - mas não do isolamento - de domínios científicos, que se pode encontrar uma relação genuinamente transdisciplinar entre eles. Uma relação que supera a clássica dicotomia da ciência moderna entre ciências naturais e humanas.

Com respeito à objetividade do conhecimento científico, a ciência pós-moderna situa essa questão em outras bases. Diferentemente da proposta científica moderna, na pós-moderna objetividade não está pari passu com a neutralidade. A objetividade "decorre ainda da aplicação sistemática de métodos que permitam identificar os pressupostos os preconceitos os valores e os interesses que subjazem à investigação científica supostamente desprovida deles [sic]" (Santos, 2000, p. 31). No entanto, isso não tem a pretensão de operar uma separação radical entre fatos e valores, ficando a ciência no campo puro dos fatos. Trata-se justamente de mostrar que tal separação não é possível, isto é, a ciência não tem como se livrar dos valores, mas, no limite, lida sempre com a relação de interdependência fatos-valores.

A busca pela objetividade torna-se premente para uma filosofia da ciência historicamente orientada, que considera a história da ciência também como uma história de cientistas individuais ou grupo de cientistas na defesa de suas ideias, mostrando que ciência é, antes de tudo, o comportamento do cientista. Esse aspecto foi destacado por Kuhn (2006) ao 
indicar uma constelação de fatores que participam do avanço da ciência, tais como os psicológicos (reorientação gestáltica promovida pelo paradigma), os sociológicos (comunidades científicas orientando a prática do cientista individual), os normativos (valores e crenças orientando a escolha de teorias), e os institucionais (sociedades científicas, jornais, revistas). Bourdieu (1983) complementa a lista, mostrando que fatores epistemológicos e ideológicos não estão isolados, mas articulam-se dialeticamente no contexto científico: mesmo aquelas tomadas de posição que significam contribuições ao progresso científico, ou que se expressam na forma de disputas teóricas ou epistemológicas, podem ser também influenciadas por posições políticas e interesses em luta no interior da ciência.

Para a ciência pós-moderna, a realidade é inacabada, sendo seus contornos delimitados pelo toque de mãos humanas. Por conseguinte, o paradigma emergente não pode ser apenas um paradigma científico; ele deve ser também um paradigma social. Tendo isso em vista, Santos (1987/2004) declara que o modelo de ciência pós-moderna é "um paradigma de um conhecimento prudente para uma vida decente" (p. 60). Ele explica:

\begin{abstract}
Com esta designação quero significar que a natureza da revolução científica que atravessamos é estruturalmente diferente da que ocorreu no século XVI. Sendo uma revolução científica que ocorre numa sociedade ela própria revolucionada pela ciência, o paradigma a emergir dela não pode ser apenas um paradigma científico (o paradigma de um conhecimento prudente), tem de ser também um paradigma social (o paradigma de uma vida decente). (Santos, 1987/2004, p. 60)
\end{abstract}

No entanto, o papel social da ciência não pode mais ser defendido por meio de metanarrativas, típicas do pensamento moderno, que preconizavam o progresso da sociedade e a emancipação da humanidade mediante a revelação de uma realidade objetiva promovida pelo conhecimento científico (Lyotard, 1979). Trata-se, isto sim, da ciência reconhecer sua natureza social e discutir consequências éticas e políticas de suas intervenções na natureza e na sociedade.

Com efeito, a ciência pós-moderna põe em xeque a dicotomia entre fatos e valores, incitando um debate acerca de outras possibilidades de relação entre eles. Embora a distinção absoluta entre fato e valor tenha sinalizado um abandono gradativo do princípio autoridade da escolástica e tenha sido responsável pelo próprio surgimento do campo da ciência natural (Mariconda, 2006), ela não apresenta mais esse caráter progressista em virtude das transformações que ocorreram na relação entre ciência e sociedade (Marcuse, 1967/2009). As consequências planetárias da tecnociência e a subjugação das questões científicas a critérios políticos e econômicos reacendem a necessidade de a ciência pensar seu papel e lugar na sociedade. A ciência, como diz Morin (1990/2008), não pode mais ser um conhecimento desinteressado - desinteressado pelos interesses políticos e econômicos que se utilizam do conhecimento científico. Em suma, o empreendimento científico não pode mais ser marcado por uma ausência de responsabilidade - uma irresponsabilidade que ganhou grandes proporções com a administração tecnoburocrática e a hiperespecialização da ciência (Morin, 1990/2008).
Nessa perspectiva, dizer que a intenção do pesquisador é pura, que é motivado simplesmente pela curiosidade; que ao trabalhar em seu gabinete ou laboratório não pode antever se suas descobertas terão efeito benéfico ou destrutivo para a sociedade, e que, em última análise, a aplicação de seus achados será feita por técnicos com o aval de políticos, não justifica a neutralidade do cientista perante as consequências sociais da ciência (Marcuse, 1967/2009). Isso porque há um circuito de retroalimentação entre ciência e sociedade: "o desenvolvimento social e a aplicação da ciência determinam, em considerável medida, o posterior desenvolvimento conceitual interno da ciência" (Marcuse, p. 161).

Desse modo, a questão da responsabilidade social da ciência e dos cientistas passa a ser vista como algo inerente à própria atividade científica:

A ciência está hoje em uma posição de poder que traduz quase imediatamente avanços puramente científicos em armas politicas e militares de uso global e eficiente. O fato de que a organização e o controle de populações inteiras, tanto na paz quanto na guerra, tornou-se, em sentido estrito, um controle e organização científicos (dos aparelhos domésticos técnicos mais comuns até os mais sofisticados métodos de formação da opinião pública, da publicidade e da propaganda) une inexoravelmente a pesquisa e os experimentos cientificos com os poderes e planos do establishment econômico, político e militar. Consequentemente, não existem dois mundos: o mundo da ciência e o mundo da política (e sua ética), o reino da teoria pura e o reino da prática impura - existe apenas um mundo no qual a ciência, a política e a ética, a teoria e a prática estão inerentemente ligadas. (Marcuse, 1967/2009, p. 160)

Em vista disso, discussões acerca das consequências éticas e políticas da ciência ganham expressão: objetividade e efetividade da ciência passam a ser também uma questão de prática social (Bernstein, 1983; Santos, 2000). Entretanto, endossar a dimensão ético-política da ciência não significa, mais uma vez, abandonar a racionalidade científica. Trata-se, agora, de uma racionalidade voltada para as relações dos homens entre si e com o mundo natural. A racionalidade a ser construída passa necessariamente pelo crivo das opções éticas. Em última instância, o fazer científico, mais do que nunca, reclama não só uma reflexão sobre a adequação de teorias, métodos e técnicas aos seus assuntos de interesse, mas, principalmente, uma discussão de suas consequências ético-políticas.

Esse quadro mostra que o debate sobre uma proposta diferente de ciência é robusto; e cada campo científico procura contribuir à sua maneira com a configuração desse paradigma emergente. E a Análise do Comportamento? Como ela tem se posicionado nesse cenário? Kvale (1992/1994) argumenta que a participação da Psicologia nesse tema tem sido pouco expressiva. Há várias razões para isso (Kvale, 1992/1994, pp. 10-11). Uma delas é que a Psicologia ainda encontra resistência em discutir questões de ordem ontológica e epistemológica - com o receio do fantasma da metafísica acaba sucumbindo ao fetiche do método (Machado, Lourenço \& Silva, 2000). Será que essas críticas se estendem à Análise do Comportamento? Enfim, a ciência skinneriana poderia contribuir com esse debate? 


\section{Análise do Comportamento: ciência moderna ou pós-moderna?}

Em diferentes momentos, Skinner (1956/1999a, 1974) defende que a Análise do Comportamento e sua filosofia, o Behaviorismo Radical, têm a possibilidade de instruir o discurso da filosofia da ciência esclarecendo a natureza do conhecimento científico. Não obstante, a Análise do Comportamento pode se situar de diferentes maneiras nessa discussão. Isso porque o texto skinneriano apresenta uma abertura tanto para o modelo de ciência moderno quanto pós-moderno (Abib, 1999; Moxley, 1999, 2001). Essas possibilidades do texto skinneriano foram bem captadas por Moxley (1999) ao mostrar que há pelo menos dois "Skinners": um moderno e outro pós-moderno - uma tese consistente com a concepção behaviorista radical de que vários "eus" podem coexistir sob a mesma pele. Em consonância com essa tese, seguem algumas características desses dois "Skinners".

\section{O "Skinner moderno"}

A obra de B. F. Skinner (1904-1990) é vasta - englobando praticamente sessenta anos de intensa publicação acadêmica (1930 a 1990) - e dinâmica - posto que marcada por profundas mudanças em seus conceitos basilares. Para Moxley $(1999,2001)$, há um predomínio de aspectos modernos até o ano de $1945^{3}$. Dentre eles destaca-se o emprego do reflexo como o modo de "explicação" do comportamento, bem como o compromisso com teses deterministas de ciência decorrentes desse modelo (Moxley, 1999, 2001; Laurenti, 2009). Ainda que nesse período inicial o determinismo não tenha sido anunciado explicitamente no nível ontológico (Laurenti, 2009), ele aparece com nitidez no âmbito epistemológico. Isso fica claro em algumas justificativas empregadas por Skinner (1931/1999b) para defender a possibilidade de um estudo científico do comportamento humano. Uma ciência comportamental é possível, pois seu objeto de estudo (o comportamento) é capaz de ser descrito por conceitos (como o de reflexo) que encerram relações necessárias entre estímulo e resposta. Skinner (1931/1999b) elucida:

O conceito de reflexo é importante na descrição do comportamento porque é, por definição, um enunciado da necessidade dessa relação. A demonstração da necessidade é em última análise uma questão empírica: observa-se que uma dada resposta segue invariavelmente um dado estímulo, ou exceções a essa regra podem ser independentemente descritas. (Skinner, $1931 / 1999$ b, p. 495)

Em relações de necessidade, o evento antecedente funciona, ao menos, como uma condição causalmente suficiente para a ocorrência do evento consequente (Mill, 1843/1979).

3 Embora delimite as características modernas e pós-modernas da proposta skinneriana em períodos, Moxley $(1999,2001)$ destaca que esses "Skinners" não estão distribuídos de maneira tão homogênea, de sorte que, amiúde, eles podem se sobrepor. Assim, ecos do modelo moderno de ciência podem ressoar até mesmo nas últimas décadas da produção intelectual de Skinner, bem como elementos pós-modernos já podem ser encontrados em germe em alguns textos iniciais.
Isto é, a ocorrência de um evento fixa de maneira inexorável e inequívoca a ocorrência de outro evento - uma tese central em propostas de ciência deterministas (Earman, 1986; Mill, 1843/1979). Subentende-se, aqui, que o determinismo insurge como uma cláusula de cientificidade na concepção skinneriana de ciência (Laurenti, 2009). Para Moxley (1999, 2001), esse "necessitarismo" ou determinismo captura os elementos de abstrações descontextualizadas, necessidade permanente e fontes antecedentes de certeza típicas da tradição de ciência moderna.

Enquanto relações necessárias entre estímulo e resposta demarcavam o campo de uma ciência do comportamento, as relações variáveis ou probabilísticas não poderiam fundamentar um sistema com pretensões científicas (Skinner, 1931/1999b). Nesse contexto, variabilidade e probabilidade seriam nada mais que um atestado de ignorância de outras variáveis que controlariam as respostas sob investigação. Ao discutir sobre as vantagens do reflexo ser um conceito adequado à descrição do comportamento, Skinner menciona justamente que as eventuais variações que possam aparecer na correlação entre estímulo e resposta não afetarão a necessidade da relação reflexa, uma vez que essas variações serão explicadas por terceiras variáveis. O seguinte trecho elucida o ponto:

Entretanto, há um segundo campo de investigação [do reflexo] que está voltado às variações em qualquer aspecto de uma correlação que podem aparecer na comparação com eliciações sucessivas (. . .). Existem variações significativas no valor dos termos na Equação $[R=f(S, A)]$. Elas não desafiam a necessidade da relação expressa nela [na equação] (como poderiam fazer se fossem menos ordenadas), mas requerem que, na descrição do reflexo, sejam consideradas terceiras variáveis (p. 500).

Ainda afinado com os pressupostos do modelo de ciência moderno, Skinner anunciou compromissos com o empirismo e o positivismo, cujo epítome é encontrado nos livros O Comportamento dos Organismos e Walden II (Moxley, 1999, 2001, 2006). Em O Comportamento dos Organismos o próprio Skinner (1938/1991) já declarou que seu sistema era positivista: "na medida em que o método científico é considerado, o sistema (...) pode ser caracterizado como segue. É positivista. Restringe-se à descrição ao invés da explicação"' (p. 44). É também empirista, uma vez que a produção de conhecimento e a inserção de conceitos em um sistema científico devem passar pelo crivo da observação. Por exemplo, termos como reflexo e extinção são legítimos em uma ciência do comportamento, pois "são usados simplesmente para reunir grupos de observações, afirmar regularidades, e expressar propriedades do comportamento que transcendem instâncias singulares" (Skinner, 1938/1991, p. 44). Sob essa ótica, a ciência do comportamento deveria produzir leis e conceitos sobre relações assentadas em eventos passíveis

4 Embora Skinner não tenha mencionado que tipo de positivismo ele está filiando seu sistema, é provável que se trate do positivismo machiano, que sustenta a redução da explicação à descrição ( $c f$. Mach, 1893/1960, pp. 6 e 325). Isso também ganha apoio ao constatarmos que no livro $O$ comportamento Organismos, Skinner menciona o físico Mach, e também, em obra posterior ( $c f$. Skinner, 1989, p. 122), admita a influência dele na elaboração desse livro. 
de serem observados, com o risco de esbarrar na metafísica, caso transgredisse o campo da observação.

Embora defendesse a possibilidade de haver uma ciência do comportamento com leis e conceitos próprios, Skinner (1947/1999c), em alguns momentos, pareceu hesitante com relação à impossibilidade de redução entre teorias científicas: "podemos assumir, por fim, que fatos e princípios da psicologia serão redutíveis não somente à fisiologia, mas, através da bioquímica e química, à física e à física subatômica. Mas, sem dúvida, essa redução ainda está longe de ser alcançada" (p. 349). Essa passagem pode sugerir a ideia de que uma redução completa não foi levada a cabo por questões de natureza metodológica, decorrentes do parco desenvolvimento técnico-científico, e não pelo fato de os fatos e leis envolvidos tratarem de fenômenos com qualidades e propriedades irredutíveis. Essa suposta nuance reducionista daria visibilidade ao "Skinner-moderno".

Tendo ainda no horizonte a proposta de ciência moderna, o livro Walden II, a despeito de ser uma ficção, uma utopia, é heuristicamente útil para captar algumas concepções de ciência e de sua relação com a sociedade na perspectiva skinneriana. Isso porque, para Skinner (1989), a noção de utopia não parece ser sinônimo de quimera. Ele sugere que Walden II, mesmo sendo uma descrição imaginativa de uma sociedade ideal, é passível de ser um dia realizada. Muito tempo depois da publicação de Walden II, ao debater a educação americana conjecturando uma escola do futuro, Skinner (1989) indaga: "Estou dando a você um sonho utópico, uma Walden II educacional? Em certo sentido, sim. Mas utopias se tornam realidade. A instituição chamada Casa de Salomão na Nova Atlântida de Francis Bacon trouxe a ciência ao governo, e ela tornou-se o modelo para a Royal Society" (p. 95, grifos meus). Vale assinalar que Skinner mudou substancialmente suas posições sobre ciência esboçadas em Walden II (Moxley, 2006). Não obstante, é possível encontrar nessa utopia algumas suposições consistentes com a ciência moderna, notadamente, as afinidades da ciência skinneriana com o cientificismo - a ideia de que a ciência é um conhecimento superior (ou, no limite, a única forma de conhecimento) em relação a outras possibilidades de compreensão humana da realidade (Köche, 2002). Uma das expressões do cientificismo é a valorização exacerbada de noções científicas em diversos campos da vida prática ou moral, como se verifica na ideia de emancipação da humanidade pelo avanço do conhecimento científico.

A superioridade do conhecimento científico fica evidente em vários momentos em Walden II. Um deles encontra-se na possibilidade de que uma atitude encorajada pelo método experimental poderia sanar de maneira inequívoca problemas sociais: "Uma atitude constantemente experimental em relação a tudo - é disso que precisamos. Soluções para problemas de todo o tipo se seguem quase milagrosamente" (Skinner, 1948/1973, p. 31). A supremacia do conhecimento científico anuncia-se, outrossim, nos processos de tomada de decisão. Em última instância, as decisões ficavam a cargo dos detentores do saber científico, os planejadores e os administradores. Por exemplo, Frazier ${ }^{5}$ admite que a constituição em Walden

5 No livro Walden II há dois personagens principais, Frazier e Burris, de cujo diálogo pode-se extrair algumas pressuposições científicas de
II não poderia ser alterada por meio do voto dos membros, "[a constituição] pode ser mudada por um voto unânime dos Planejadores e de dois terços dos votos dos Administradores. As pessoas não estão em melhor posição para mudar a constituição do que para decidir sobre suas práticas" (Skinner, 1948/1973, p. 266). Já o Código de Walden II, uma espécie de regra de conduta, poderia ser alvo de crítica por parte dos membros, "quanto à discordância, qualquer um pode examinar a experiência a partir da qual uma regra foi introduzida no Código. Pode argumentar contra a sua inclusão e pode apresentar as suas próprias provas" (Skinner, 1948/1973, p. 167). Entretanto, no final das contas, a mudança caberia aos administradores e planejadores. Dando continuidade ao trecho: "se os Administradores recusam mudar a regra, ele [o membro da comunidade] pode apelar aos Planejadores, mas em nenhum caso, deve discutir sobre o Código com os demais membros. Há uma regra contra isso" (Skinner, p. 167).

Vale ressaltar que essas passagens devem ser contextualizadas nas condições particulares de Walden II, como o emprego do reforço positivo pelos administradores, e certo desinteresse por parte dos membros da comunidade em planejar e governar ( $c f$. Skinner, 1948/1973, p. 169), posto que as relações dos administrados e planejadores com os membros eram de tolerância e afeição, ao invés de dominação e admoestação ( $c f$. Skinner, p. 163), e as condições para a saúde, lazer, felicidade, conforto e divertimento eram garantidas ( $c f$. Skinner, p. 171). Todavia, a ausência de uma participação ativa dos membros da comunidade nos processos de tomada de decisão em Walden II, em contraste com o poder decisivo dos administradores e planejadores, sugere uma supervalorização do conhecimento científico do especialista em relação a outras formas de conhecimento. Em tese, essa disparidade parece subscrever tacitamente a clássica dicotomia moderna entre fatos e valores. Os fatos, que estão do lado da ciência (analogamente dos administradores e planejadores), são os árbitros absolutos de questões conflitantes; ao passo que os valores, pertencentes ao saber comum (representados, aqui, pelos membros da comunidade), são destituídos desse poder.

A essa acusação, Frazier poderia replicar que em Walden II não há dicotomia entre fatos e valores; trata-se apenas de padrões de respostas sob controle de estímulos, tudo é comportamento, ou seja, tudo é fato. No entanto, fica incólume a racionalidade da ciência moderna, agora, acirrada a ponto de resolver a dicotomia reduzindo valores a fatos. Além disso, nesse contexto, onde tudo é fato, os cientistas, em Walden II, não só continuariam a elaborar os códigos morais, como de-

Skinner. O primeiro personagem, Frazier, defende Walden II, mostrando as vantagens de uma sociedade calcada em princípios científicos, já o segundo, Burris, sempre lança dúvidas sobre essa proposta. Skinner parece se identificar mais com Frazier. Ao ser indagado se Walden II tinha sido escrito de modo satírico, Skinner (1983/1984a) replicou: “as visões de Frazier são essencialmente as minhas próprias visões - mais agora do que quando eu escrevi” (p. 9). Em outra situação, quando Skinner foi interpelado quanto às suas motivações para escrever Walden II, ele disse "isso foi uma espécie de auto-terapia, com o meu lado Burris resistindo a aceitar o lado Frazier'. Como coloquei em uma palestra na Columbia Teachers College em 1960, 'Frazier logo começou a dizer coisas que eu ficaria surpreso de ouvir de meus próprios lábios ... mas, tendo considerado todo o padrão de seu pensamento, vi as conexões entre suas partes, e me tornei, um ano ou dois depois que terminei, um completo frazierano"'(Skinner, 1983/1984a, p. 180). 
veriam ser considerados como os únicos capazes de fazê-lo, já que seriam os mais habilitados para lidar com fatos. Assim, o cientificismo mantém-se tanto na defesa da dicotomia entre fatos e valores, dando prioridade cognitiva aos fatos, quanto na redução dos valores aos fatos. Em ambas alternativas os fatos permanecem puros, o que vai contra a tese científica pós-moderna que já concebe fatos impregnados por valores.

\section{O "Skinner pós-moderno"}

Mudanças significativas no âmbito da ontologia, epistemologia e ética marcam as concepções científicas do "Skinner pós-moderno". A faceta pós-moderna aparece pela primeira vez de forma mais evidente em 1945, com a publicação do artigo A Análise Operacional de Termos Psicológicos, no qual Skinner apresenta a contingência tríplice probabilística para explicar o comportamento verbal (Moxley, 2001). A partir desse período, as noções de probabilidade e variabilidade parecem adquirir um estatuto diferente na ontologia e epistemologia skinnerianas, deixando de ser tratadas como mera ignorância das causas.

Em 1953, no livro Ciência e Comportamento Humano, Skinner faz um pronunciamento explícito sobre a natureza do comportamento. Ele diz: o comportamento é "um processo e não uma coisa" (Skinner, 1953, p. 15). E mais: é um processo "mutável, fluido e evanescente" (Skinner, p. 15). Nesse livro, em especial, Skinner (1953) separa o conceito de operante do de reflexo ${ }^{6}$, e passa a empregar o primeiro como um modelo predominante de explicação do comportamento ontogenético. No modelo operante, a explicação do comportamento remete a contextos amplos com uma ênfase especial nas consequências das ações. Essa ênfase parece ser consistente com filosofias pragmatistas (Moxley, 1999, 2001) - uma relação que foi endossada pelo próprio Skinner (1979) em uma entrevista:

A palavra "pragmatismo", por exemplo, teve muitos significados diferentes em épocas distintas. Primeiro, ela serviu para chamar a atenção para as consequências de nossas ações. Posteriormente, Charles Sanders Peirce aplicou essa noção de consequências ao que ele chamou de 'ideias' ou 'conceitos'. A totalidade de uma ideia ou conceito é a totalidade de suas consequências ou efeitos. (. . .) Isso está muito próximo, eu penso, de uma análise operante da maneira em que respondemos aos estímulos. A totalidade de nosso conhecimento ou de nossa descrição de um estímulo é o que acontece quando respondemos a ele. (p. 48)

A explicação do comportamento em termos das consequências das ações ganha novo escopo e magnitude no

$6 \quad$ Vale mencionar que Skinner empregou o termo operante em textos anteriores (Skinner, 1937/1999d, 1938/1991). Não obstante, ali o operante ainda era considerado como um tipo de reflexo, como se verifica no texto Dois tipos de reflexo condicionado: Uma réplica a Konorski e Miller (Skinner, 1937/1999d). Aqui, Skinner diferencia o reflexo em dois tipos (Tipo S e Tipo R) pelo fato de serem resultado de processos de condicionamento distintos, encerrando relações diferentes entre estímulo e resposta: "todos os reflexos do Tipo R são, por definição, operantes, e todos do Tipo S são respondentes” (p. 538). sistema científico skinneriano com o modelo de seleção pelas consequências. Nesse modelo, Skinner (1981/1984b) discute o papel das consequências pautando-se na teoria evolucionária darwiniana. As consequências passam a selecionar o comportamento em três níveis evolutivos: filogenético, ontogenético e cultural. No primeiro nível, padrões inatos de comportamento (reflexos incondicionados e instintos) são selecionados por consequências de sobrevivência da espécie; no segundo, comportamentos de indivíduos (operantes) são selecionados por consequências reforçadoras, e no terceiro nível práticas culturais são selecionadas por consequências de sobrevivência das culturas (Skinner, 1981/1984b).

Mas a seleção de comportamentos só é possível se houver variação. Com efeito, variações comportamentais são selecionadas pelas consequências que produzem, dando origem a novos comportamentos. Contudo, a noção de variabilidade ganha outra acepção no modelo consequencialista-selecionista skinneriano. Não se trata apenas de desconhecimento da totalidade de variáveis controladoras. A variabilidade passa a ser considerada também como um elemento intrínseco ao fenômeno comportamental: “a existência de variações está na natureza do comportamento, assim como está na natureza de um traço genético e, da mesma forma, novos comportamentos e novos genomas emergem quando variações são selecionadas por suas consequências" (Skinner, 1989, p. 129).

Essas mudanças aproximam a ciência skinneriana de uma visão de mundo ou cosmologia indeterminista (Laurenti, 2009; Moxley, 2007), defendida também por filósofos pragmatistas (James, 1963/1967; Peirce, 1892/1992; Pepper, 1942/1961), e por cientistas e filósofos das ciências de orientação darwinista (Lewontin, 1998/2002; Mayr, 2004/2005). Para Moxley $(1999,2001)$ as afinidades com o pragmatismo e o darwinismo selecionista só vêm a realçar os elementos pós-modernos da proposta científica skinneriana.

No nível epistemológico, as noções de variabilidade e probabilidade também ganham significado cognitivo. No modelo de seleção pelas consequências o processo de variação explica, ao lado da seleção, o surgimento e a evolução de novos comportamentos (Skinner, 1981/1984b, 1989). Já com a adoção do conceito de operante na explicação do comportamento ontogenético, a probabilidade passa a descrever a dinâmica das relações entre respostas e estímulos antecedentes e consequentes (Skinner, 1953). O ambiente não impele ou força a ocorrência das ações, mas estabelece probabilidades do responder. Os estímulos antecedentes sinalizam uma probabilidade de reforçamento; já as consequências afetam a probabilidade de ocorrência de respostas do mesmo tipo no futuro (Skinner, 1953). Em suma, na ciência skinneriana o "dado básico não é a ocorrência de uma dada resposta enquanto tal, mas a probabilidade de que ela ocorrerá em um dado momento" (Skinner, 1957, p. 22). Mesmo no modelo de seleção pelas consequências, Skinner (1989) parece continuar tratando os fenômenos comportamentais pertencentes aos três níveis seletivos em termos de probabilidade. Com relação aos dois primeiros níveis, ele afirma: "tanto no condicionamento operante, quanto na seleção evolutiva de características comportamentais, as consequências alteram a probabilidade futura" (Skinner, 1953, p. 90). As práticas culturais do terceiro nível seletivo também são concebidas como probabilidades. Por exemplo, 
com respeito à prática cultural de arar a terra, Skinner disse (1989): “arar é (a) um tipo de comportamento ('arar a terra apareceu em primeiro lugar na antiga Mesopotâmia e no antigo Egito'), (b) uma probabilidade ('arar a terra depende do clima'), (c) uma instância ('o fazendeiro está arando seu campo')" (p. 37).

$\mathrm{Na}$ medida em que Skinner (1989) entende a variação como um aspecto da natureza do comportamento, o fenômeno comportamental pode ser visto como algo mutável e variável. Em vista disso, os próprios fatos da ciência do comportamento não são fixos e imutáveis, "nós podemos falar, então, da evolução dos fatos" (Skinner, 1987, p. 88). Nesse contexto, os objetivos de previsão e controle do comportamento são também inscritos no idioma das probabilidades: "tanto a predição quanto o controle são inerentes no condicionamento operante, mas a noção é sempre [ênfase adicionada] probabilística" (Skinner, 1974, p. 226). Com efeito, a meta da ciência skinneriana não seria a busca da certeza, mas sim, de conceitos e leis que descrevam relações de dependência probabilística entre indivíduo e seu contexto natural e social.

No modelo de seleção pelas consequências, a busca por essas relações de dependência se dá no contexto de um diálogo transdisciplinar entre as "ciências da variação e seleção" (Skinner, 1990a, p. 1208), quais sejam: Etologia, Análise do Comportamento e parte da Antropologia, e as ciências do corpo-com-cérebro, a Fisiologia e a Neurologia. Embora Skinner (Skinner, 1989, p. 54-56) defenda que um entendimento da complexidade do comportamento só possa se dar com a articulação dessas ciências, a relação entre elas não parece ser encorajada por um programa reducionista de ciência. No caso da relação entre as ciências da variação e seleção, Skinner (1981/1984b, p. 480, 1989, pp. 54-56) parece ser agora mais categórico em relação à autonomia de campos científicos. Por exemplo, ele condena a análise do fenômeno de um nível seletivo com os princípios e conceitos de outro nível, como quando se diz que "genes são altruístas e agressivos" (Skinner, 1989 , p. 55), ou quando se fala de "linguagem das abelhas" (Skinner, 1989, p. 54), ou ainda, de "um gene para a religião" (Skinner, 1989, p. 55). É certo que pode haver semelhanças na topografia do comportamento em cada um dos níveis de variação e seleção, o que pode "obscurecer diferenças nas variáveis controladoras” (Skinner, 1989, p. 55). Independentemente disso, Skinner é enfático (1981/1984b): "a similaridade estrutural não atesta um princípio gerador comum” (p. 480). Assim, cada nível seletivo e seus respectivos campos científicos encerram fenômenos e processos distintos, com qualidades próprias que não podem ser reduzidas a outros níveis de variação e seleção. Essa atitude não reducionista também se verifica na relação das ciências da variação e seleção com a Fisiologia e a Neurologia. Mesmo dizendo "nunca questionei a importância da fisiologia ou em particular da ciência do cérebro ou sua relevância para o comportamento" (Skinner, 1989, pp. 129-130), Skinner defende a autonomia desses domínios científicos, declarando que cada um deles "com seus próprios instrumentos e métodos" ( $p$. 130) pode ajudar na tarefa de compreensão do comportamento. Essa característica transdisciplinar do modelo de seleção por consequências encoraja aproximações da ciência skinneriana com a epistemologia da complexidade (Abib, 2004) - uma epistemologia em franca oposição ao caráter simplificador e reducionista da ciência moderna (Morin, 1990/2008).

Outros aspectos epistemológicos da ciência skinneriana exibem afinidades com a ciência pós-moderna. Abib (1999) mostra que na epistemologia pragmatista de Skinner, ciência é comportamento do cientista, mais especificamente, "é comportamento verbal dos cientistas regido por um corpo de regras para ações efetivas" (p. 239). Sendo assim, a própria observação e a produção do conhecimento científico são marcadas pela combinação das variáveis da história de vida do cientista com variáveis sociais, culturais e econômicas da comunidade verbal de cientistas ao qual pertence. Com isso, Skinner $(1953,1974)$ admite que a observação não é pura, e que a produção de conhecimento científico não é neutra e desinteressada, o que acaba distanciando a ciência do comportamento do empirismo. Ademais, Skinner (1971, 1981/1984b) abandona a dicotomia entre fatos e valores - "não há um mundo de valor distinto de um mundo de fatos" (Skinner, 1981/1984b, p. 479), e atribui estatuto cognitivo aos juízos de valor (Abib, 1999). Tais aspectos afastam a ciência skinneriana da tradição de pensamento positivista.

Na ótica de Abib (1999), então, “a epistemologia do behaviorismo radical é mais solidária com o pragmatismo do que com o positivismo e o empirismo" (p. 241). A faceta pragmatista da epistemologia skinneriana também se evidencia na justificação do conhecimento como uma questão de prática social. Nessa perspectiva, a efetividade do conhecimento científico não é apenas traduzida em termos da possibilidade de compreender, prever e controlar o comportamento. A efetividade também diz respeito à possibilidade de a ciência produzir consequências éticas e políticas que se traduzam em projetos que promovam um mundo melhor, mais igualitário e mais harmonioso com a natureza e com os outros homens (Abib, 2001).

Se em Walden II a sociedade estava subjugada à ciência, agora Skinner (1990b) defende uma relação inversa: a ciência está subsumida à sociedade. O papel da ciência é o de trazer o futuro para o presente. Em outras palavras, é mostrar as consequências postergadas das intervenções humanas na natureza e sociedade, tais como: superpopulação, esgotamento de recursos naturais, pobreza, radiação solar e nuclear, e assim por diante (Skinner, 1990b). Esse conhecimento pode ser usado por outras agências como educação, religião, mídia e indústria para mudar práticas que ameaçam o futuro da natureza e de outras gerações. Mais importante ainda é que a sociedade, mediante a organização de protestos, pode se voltar contra essas agências quando elas não levam em consideração as consequências prejudiciais de suas práticas (Skinner, 1990b). Com efeito, a mudança social é uma transformação de práticas culturais promovida não apenas pela ciência, mas por toda a sociedade. Mudanças que têm caráter emergencial, pois "o que temos feito com nosso destino pode não ser o testamento que queremos deixar para o mundo" (Skinner, 1990b, p. 106). 


\section{Considerações Finais}

As distinções entre discurso moderno e pós-moderno recortam um cenário propício para destacar as tendências ontológicas, epistemológicas e éticas de propostas científicas (Santos, 1987/2004, 1989/2003). Esse quadro pode ajudar a refletir os compromissos filosóficos implícitos no modelo de ciência analítico-comportamental. O texto skinneriano guarda afinidades tanto com o discurso científico moderno quanto pós-moderno, abrindo, ao menos, dois caminhos distintos à Análise do Comportamento. No primeiro caso, ela é conduzida ao determinismo, positivismo, empirismo, reducionismo, e cientificismo (Moxley, 1999, 2001, 2006). No segundo caso, ela é encaminhada ao selecionismo, pragmatismo, probabilismo (ou indeterminismo científico), transdisciplinaridade, e a uma reflexão ético-política da atividade científica (Abib, 1999, 2001; Laurenti, 2009; Moxley, 1999, 2001).

Resta, então, indagar: qual caminho está sendo trilhado pela Análise do Comportamento atualmente? Uma resposta a essa questão pode ser buscada nas práticas científicas dos analistas do comportamento. As escolhas teórico-metodológicas, o investimento em cada campo de pesquisa (factual, aplicada, conceitual), a natureza de suas publicações, o conteúdo dos debates no interior da comunidade de analistas do comportamento e de outras comunidades científicas, o diálogo com o senso comum são consistentes com o "Skinner moderno" ou pós-moderno?

A busca por essas respostas não redunda em mera disputa verbal vazia ou em especulação ingênua, pois os pressupostos dos modelos moderno e pós-moderno de ciência situam a Análise do Comportamento em tramas conceituais incompatíveis. Por conseguinte, eles conduzem a práticas distintas, delimitando inclusive com quais ciências e outros campos do saber a ciência comportamentalista tem condições de estabelecer um diálogo virtuoso. Tais discussões reclamam da Análise do Comportamento uma reflexão profunda sobre suas práticas científicas contemporâneas, o que trará consequências para a própria sobrevivência dessa ciência como prática cultural.

\section{Referências}

Abib, J.A. D. (1999). Behaviorismo radical e discurso pós-moderno. Psicologia: Teoria e Pesquisa, 15, 237-247.

Abib, J. A. D. (2001). Behaviorismo radical como pragmatismo na epistemologia. In H. J. Guilhard, M. B. B. P. Madi, P. P. Queiroz \& M. C. Scoz (Eds.), Sobre o comportamento e cognição (vol. 8, pp. 158-161). Santo André. ESETec.

Abib, J. A. D. (2004). O que é comportamentalismo? In M. Z. S. Brandão, F. C. S. Conte, F. S. Brandão, U. K. Ingberman, V. L. M. da Silva \& S. M. Oliani (Eds.), Sobre comportamento e cognição (vol. 13, pp. 52-61). Santo André: ESETec.

Bacon, F. (1979). Novum organum (J. A. R. de Andrade, Trad.). In V. Civita (Ed.), Coleção Os Pensadores (pp. 05-231). São Paulo: Abril Cultural (Trabalho original publicado em 1620).

Bauman, Z. (2001). Modernidade líquida (P. Dentzien, Trad.). Rio de Janeiro: Zahar.

Bernstein, R. (1983). Beyond objectivism and relativism: Science, hermeneutics and praxis. Philadelphia: University of Pennsylvania Press.
Bourdieu, P. (1983). O campo científico (P. Montero \& A. Auzmendi, Trads.). In R. Ortiz (Ed.), Pierre Bourdieu: Sociologia (pp. 122155). São Paulo: Ática.

Comte, A. (1978). Curso de filosofia positiva (J. A. Giannotti, Trad.). In V. Civita (Ed.), Coleção Os Pensadores (p. 03-39). São Paulo: Abril Cultural (Trabalho original publicado em 1830-42).

Earman, J. (1986). A primer on determinism. Dordrecht: Reidel.

Galilei, G. (1987). O ensaiador (H. Barraco, Trad.). In G. Galilei (Ed.), Coleção Os Pensadores (pp. 7-140). São Paulo: Nova Cultural (Trabalho original publicado em 1623).

Galilei, G. (2004). Diálogo sobre os dois máximos sistemas do mundo ptolomaico e copernicano (P. R. Mariconda, Trad.). São Paulo: Discurso Editorial/Imprensa Oficial do Estado de São Paulo (Trabalho original publicado em 1632).

Geertz, C. (1973). The interpretation of culture. New York: Basic Books.

Giddens, A. (2003). Modernidade e identidade (P. Dentzien, Trad.). Rio de Janeiro: Jorge Zahar.

Heisenberg, W. (2004). A descoberta de Planck e os problemas filosóficos da física atômica (G. K. Guinsburg, Trad.). In M. Born, P. Auger, E. Schrödinger \& W. Heisenberg (Eds.), Problemas da fisica moderna (pp. 9-27). São Paulo: Perspectiva (Trabalho original publicado em 2000).

Heisenberg. W. (1999). Physics and philosophy: A revolution in modern science. New York: Prometheus Books (Trabalho original publicado em 1958).

James, W. (1967). Alguns problemas metafísicos considerados pragmaticamente (C. da Silva, Trad.). In Pragmatismo e outros ensaios (pp. 63-81). Rio de Janeiro: Lidador (Trabalho original publicado em 1963).

Köche, J. C. (2002). Fundamentos de metodologia cientifica $\left(20^{\mathrm{a}}\right.$ ed. atualizada). Petrópolis: Vozes.

Kuhn, T. S. (2006). O caminho desde a estrutura (C. Mortari, Trad.). São Paulo: Editora Unesp.

Kvale, S. (1994). Psychology and postmodernism. London: Sage Publications (Trabalho original publicado em 1992).

Laplace, P. S. (1951). A philosophical essay on probabilities. New York: Dover Publications (Trabalho original publicado em 1814).

Laurenti, C. (2009). Determinismo, indeterminismo e Behaviorismo Radical. Tese de Doutorado, Universidade Federal de São Carlos, São Carlos.

Lewontin, R. (2002). A tripla hélice: Gene, organismo e ambiente (J. Vegas Filho, Trad.). São Paulo: Companhia da Letras (Trabalho original publicado em 1998).

Lyotard, J-F. (1979). La condition posmoderne. Paris: Le Éditions de Minut.

Mach, E. (1960). The science of mechanics. Illinois: The Open Court Publishing Company (Trabalho original publicado em 1893).

Machado, A., Lourenço, O., \& Silva, F. J. (2000). Facts, concepts and theories: The shape of psychology's epistemic triangle. Behavior and Philosophy, 28, 1-40.

Marcuse, H. (2009). A responsabilidade da ciência. Scientiae Studia, 7, 159-164 (Trabalho original publicado em 1967).

Mariconda, P. R. (2006). O controle da natureza e as origens da dicotomia entre fato e valor. Scientiae Studia, 4, 453-472.

Mayr, E. (2005). Biologia, ciência única (M. Leite, Trad.). São Paulo: Companhia das Letras (Trabalho original publicado em 2004). 
Mill, J. S. (1979). Sistema de lógica dedutiva e indutiva (J. M. Coelho, Trad.). In C. Civita (Ed.), Coleção Os Pensadores (pp. 85-293). São Paulo: Abril Cultural (Trabalho original publicado em 1843).

Miller, D. (1997). Propensões e indeterminismo (L. P. Rouanet, Trad.). In A. O'Hear (Ed.), Karl Popper: Filosofia e problemas (pp. 147-176). São Paulo: Unesp (Trabalho original publicado em 1995).

Morin, E. (1999). Por uma reforma do pensamento (M. C. Ribas, Trad.). In A. Pena-Vega \& E. P. do Nascimento (Eds.), O pensar complexo: Edgar Morin e a crise da modernidade (pp. 21-34). Rio de Janeiro: Garamond.

Morin, E. (2008). Ciência com consciência (M. D. Alexandre \& M. A. S. Dória, Trads.) (12a ed. revista e modificada pelo autor). Rio de Janeiro: Bertrand Brasil (Trabalho original publicado em 1990).

Moxley, R. A. (1999). Two Skinners, modern and postmodern. Behavior and Philosophy, 27, 97-125.

Moxley, R. A. (2001). The modern/postmodern context of Skinner's selectionist turn in 1945. Behavior and Philosophy, 29, 121153.

Moxley, R. A. (2006). B. F. Skinner's other positivistic book: Walden II. Behavior and Philosophy, 34, 19-37.

Moxley, R. A. (2007). Ultimate realities: deterministic and evolutionary. Behavior Analyst, 30, 59-77.

Peirce, C. S. (1992). The doctrine of necessity examined. In N. Houser \& C. J. W. Kloesel (Eds.), The essential Peirce (pp. 298-311). Bloomington: Indiana University Press (Trabalho original publicado em 1892).

Pepper, S. C. (1961). World hypotheses: Prolegomena to systematic philosophy and a complete survey of methaphysics ( $\left.4^{\mathrm{a}} \mathrm{ed}.\right)$. Berkeley: University of California Press (Trabalho original publicado em 1942).

Popper, K. (1988). O universo aberto: Argumentos a favor do indeterminismo (N. F. da Fonseca, Trad.). Lisboa: Publicações Dom Quixote (Trabalho original publicado em 1956).

Prigogine, I. (2003). O fim da certeza (A. M. da Cunha, Trad.). In C. Mendes (Ed.), Representação e complexidade (pp. 47-67). Rio de Janeiro: Garamond.

Santos, B. S. (2000). A crítica da razão indolente: Contra o desperdício da experiência (vol. 1). São Paulo: Cortez.

Santos, B. S. (2003). Introdução a uma ciência pós-moderna (4a ed.). Rio de Janeiro: Graal (Trabalho original publicado em 1989).

Santos, B. S. (2004). Um discurso sobre as ciências. São Paulo: Cortez (Trabalho original publicado em 1987).

Skinner, B. F. (1953). Science and human behavior. New York: The MacMillan Company.

Skinner, B. F. (1957). Verbal behavior. Acton: Copley Publishing Group.

Skinner, B. F. (1971). Beyond freedom and dignity. New York: Alfred A. Knopf.
Skinner, B. F. (1973). Walden II: Uma sociedade do futuro (R. Moreno \& N. R. Paiva, Trads.) (1 $1^{a}$ reimpressão). São Paulo: EPU (Trabalho original publicado em 1948).

Skinner, B. F. (1974). About behaviorism. New York: Alfred A. Knopf.

Skinner, B. F. (1979). Interview with B. F. Skinner. Behaviorists for Social Action Journal, 2, 47-52.

Skinner, B. F. (1984a). A matter of consequences. New York: New York University Press (Trabalho original publicado em 1983).

Skinner, B. F. (1984b). Selection by consequences. The Behavioral and Brain Sciences, 7, 477-481 (Trabalho original publicado em 1981).

Skinner, B. F. (1987). The evolution of verbal behavior. In B. F. Skinner (Ed.), Upon further reflection (pp. 75-92). Englewood Cliffs, NJ: Prentice-Hall.

Skinner, B. F. (1989). Recent issues in the analysis of behavior. Columbus: Merrill Publishing Company and Bell \& Howell Information Company.

Skinner, B. F. (1990a). Can psychology be a science of mind? American Psychologist, 45 (11), 1206-1210.

Skinner, B. F. (1990b). To know the future. The Behavior Analyst, 13, 103-106.

Skinner, B. F. (1991). The behavior of organisms: An experimental analysis. Cambridge: B. F. Skinner Foundation (Trabalho original publicado em 1938).

Skinner, B. F. (1999a). A case history in scientific method. In J. S. Vargas (Ed.), Cumulative record: Definitive edition (pp. 108131). Acton, MA: Copley Publishing Group (Trabalho original publicado em 1956).

Skinner, B. F. (1999b). The concept of the reflex in the description of behavior. In J. S. Vargas (Ed.), Cumulative record: Definitive edition (pp. 475-503). Acton, MA: Copley Publishing Group (Trabalho original publicado em 1931).

Skinner, B. F. (1999c). Current trends in experimental psychology. In J. S. Vargas (Ed.), Cumulative record: Definitive edition (pp. 341-359). Acton, MA: Copley Publishing Group (Trabalho original publicado em 1947).

Skinner, B. F. (1999d). Two types of conditioned reflex: a reply to Konorski and Miller. In J. S. Vargas (Ed.), Cumulative record: Definitive edition (pp. 535-543). Acton, MA: Copley Publishing Group (Trabalho original publicado em 1937).

Recebido em 25.01.2011

Primeira decisão editorial em 10.08.2011

Versão final em 31.08.2011

Aceito em 05.09.2011 